\title{
The Effects of Meteorological Factors Anomalies on Oceanic Coral Reef Systems in the Northwestern South China Sea
}

\author{
Lingli Fan, Yuchun Shen \\ Guangdong Ocean University, Zhanjiang, China \\ Email: fanlingli@126.com
}

Received December 2014

\begin{abstract}
Climate warming, variation of East Asian atmospheric system have affected the Chinese offshore environment through the air-sea interaction, the coastal waters of South China Sea had been influenced, leading a corresponding impact on the coral reef growth. This paper reports on coral coverage and dominant coral species changes in Xu wen National Coral Reef Nature Reserve, examines their relationship with meteorological factors anomalies recorded by satellite. The study reveals that: compared to the period from 1979 to 2003, the temperature of surface coastal water dropped significantly in South China Sea in 2004-2008, the divergence of low layer of atmosphere over it strengthened, produced a zonal westerly anomaly field, which had an opposite direction to the local northeastern trade wind. The increasing of suspended matter in water, the decreasing of down welling in northwestern South China Sea, made the water quality deteriorating, water transparency decreased significantly, coral reef survival environment worsened, which would cause adverse effects on coral reef building capacity in the Reserve. Continued monitoring efforts are necessary to further assess the relationship between coral building capacity and in situ meteorological factors anomalies and improve the use of the dataset in future regional degradation predictions.
\end{abstract}

\section{Keywords}

Coral Reef Systems, Sea Surface Temperature, Divergence, Downwelling

\section{Introduction}

The Xuwen National Coral Reef Nature Reserve locates at $20^{\circ} 10^{\prime} 60^{\prime \prime} \mathrm{N}-27^{\prime} 00^{\prime \prime} \mathrm{N}, 109^{\circ} 50^{\prime} 20^{\prime \prime} \mathrm{E}-56^{\prime} 40^{\prime \prime} \mathrm{E}$, occupies 14378.5 hectares.

Records of coral bleaching events, coincident with temperature anomalies, have been reported in the northwestern South China Sea [1]-[4]. Bleaching occurs when stress causes corals to expel their endosymbiotic algae (zooxanthellae), which, if prolonged or particularly severe, may result in partial or complete coral mortality. Numerous stresses cause bleaching, but "mass" coral bleaching (at scales of $100 \mathrm{~km}$ or more) has only occurred 
when anomalously warm ocean temperatures, typically coupled with high subsurface light levels, have exceeded the physiological tolerances of the corals [5] [6].

Degradation of coral reefs in the South China Sea is mainly due to the effect of intensified human activities, such as Hainan Sanya corals has experienced rock mining, fishing, coastal engineering construction and diving tours damage [7]. By the double impact of increasing human activity and global warming (leading to coral bleaching), the world coral reef overall in the serious degradation in recent decades, such as the Great Barrier Reef in Australia live coral coverage decreased from $\sim 50 \%$ to $20 \%$ during 1960-2003 [8].

This paper presents reports on coral coverage and dominant coral species changes that occurred between 2004-2008 and 1997-2003 in Xuwen National Coral Reef Nature Reserve examines their correlation with the anomalies of SST, divergence, downwelling, which were recorded by satellite.

\section{Data and Method}

\subsection{Satellite Data}

Using monthly SS(Sea SurfaceTemperature)T time series from NOAA/NASA Pathfinder Advanced Very High Resolution Radiometer (AVHRR) Version 5.2 data of 1985-2007, obtained from the US National Oceanographic Data Center and GHRSST, AVHRR SST data are available at 4-km resolution, and SST values are accurate to within $0.3^{\circ} \mathrm{C}$ [9]. Another monthly SST time series from COBE SST2 and Sea-Ice data of $1850-2014,1.0^{\circ} \times$ $1.0^{\circ}$ global grid. Geometric vertical velocity (dz/dt) time series from NCEP Global Ocean Data Assimilation System (GODAS), $0.333^{\circ}$ latitude $\times 1.0^{\circ}$ longitude global grid, monthly values for 1980-2014. Divergence and $\mathrm{U}$ component of wind time series from ERA Interim, $0.75^{\circ} \times 0.75^{\circ}$ global grid, monthly values for 1979-014.

\subsection{Coral Dataset}

For this study, used data on coral coverage and dominant coral species collected by South China Sea Institute of Oceanology during 2004 and 2008 expeditions $\left(20^{\circ} 10^{\prime} 60^{\prime \prime} \mathrm{N}-27^{\prime} 00^{\prime \prime} \mathrm{N}, 109^{\circ} 50^{\prime} 20^{\prime \prime} \mathrm{E}-56^{\prime} 40^{\prime \prime} \mathrm{E}\right)$. The coral fauna in the Reserve presented 54 coral species, Goniopora duofasciata and Plesiastrea versipora, and so on, as the dominant species, most were massive or hull shape.

Reef location is marine protected area. The Xuwen national Coral Reef National Nature Reserve, created in 2009, fishing and other extractive activities are banned within it, whereas tourism activities are allowed.

In 2008 expedition, data were collected in selected 25 sites (Fig omitted). Data were collected in the Reserve from May 16th, 2008 to June 24th, 2008. During the expedition, six replicate 10-m transects were haphazardly laid at each site.

\subsection{Statistical Analysis}

Using statistical analysis, to study the temporal and spatial variation of atmospheric circulation over South China Sea, to discuss the meteorological factors how to affect coral reefs coverage and dominant species in the Reserve, such as wind, divergence, sea surface temperature (SST), and downwelling.

\section{Results}

The anomaly data for the Reserve is presented in Figure 1, the series for the satellite data is presented from 1979 to 2008 . In the Reserve, the maximum anomaly was $1.52^{\circ} \mathrm{C}$ in 1999 and $1.34^{\circ} \mathrm{C}$ in $1998.1997-2003$, positive anomalies persisted. From 1979-1996, 2004-2008, negative anomaly held a lead.

Drawing the SST difference field between 2004-2008 and 1997-2003 around the Reserve. Affected by the changes of SST in the tropical Pacific Ocean and Asia monsoon, the temporal and spatial distribution characteristics of Chinese offshore SST have changed. For the years 2004-2008, the temperature of surface coastal water in South China Sea dropped significantly, as Figure 2 showed, compared to 1997-2003, SST of the Reserve dropped by $-0.5^{\circ} \mathrm{C}$, cooling significantly greater than the subtropical western pacific.

The changes of the East Asian monsoon and atmospheric circulation adjustment would lead to changes of convergence or divergence wind field in the low layer of atmosphere, the coastal waters of South China Sea would be influenced, lead to a corresponding impact on the marine environment. Using the ERA-Interim reanalysis data to analysis $925 \mathrm{hPa}$ atmospheric circulation divergence over the South China Sea, as Figure 3 showed, 


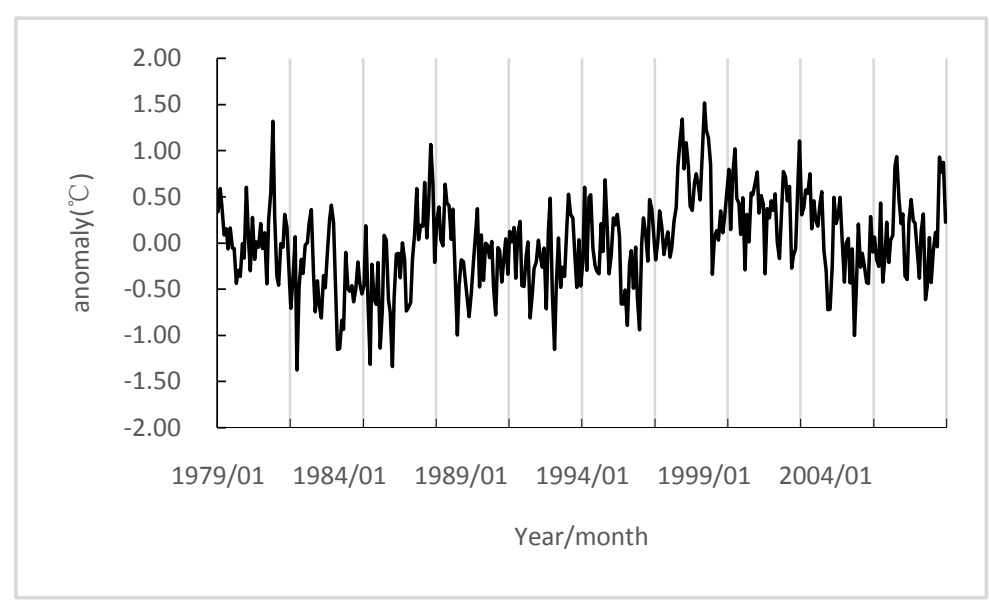

Figure 1. SST anomaly $\left({ }^{\circ} \mathrm{C}\right)$ measured by satellite (AVHRR) in Xuwen National Coral Reef National Nature Reserve from 1979 to 2008.

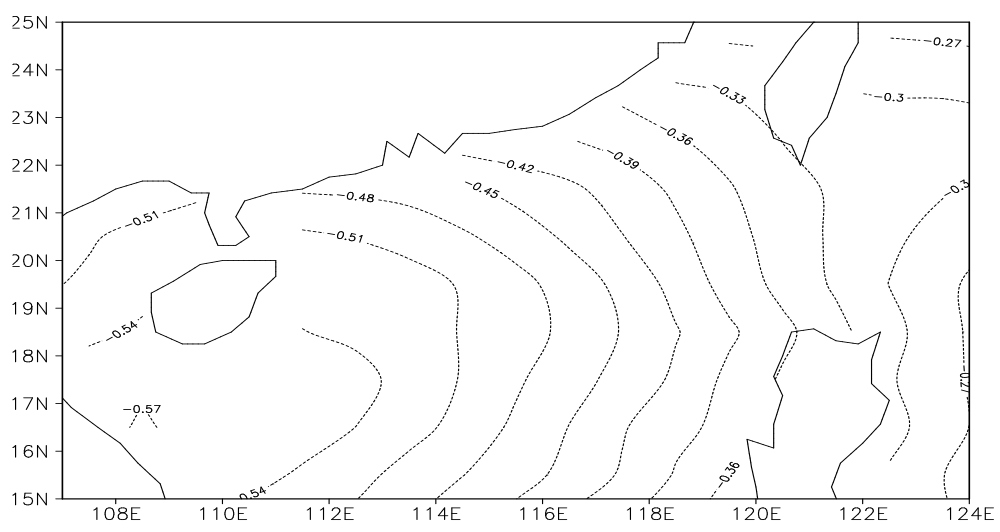

Figure 2. Spatial pattern of the SST difference $\left({ }^{\circ} \mathrm{C}\right)$ between 2004-2008 and 1997-2003 in the offshore of South China Sea.

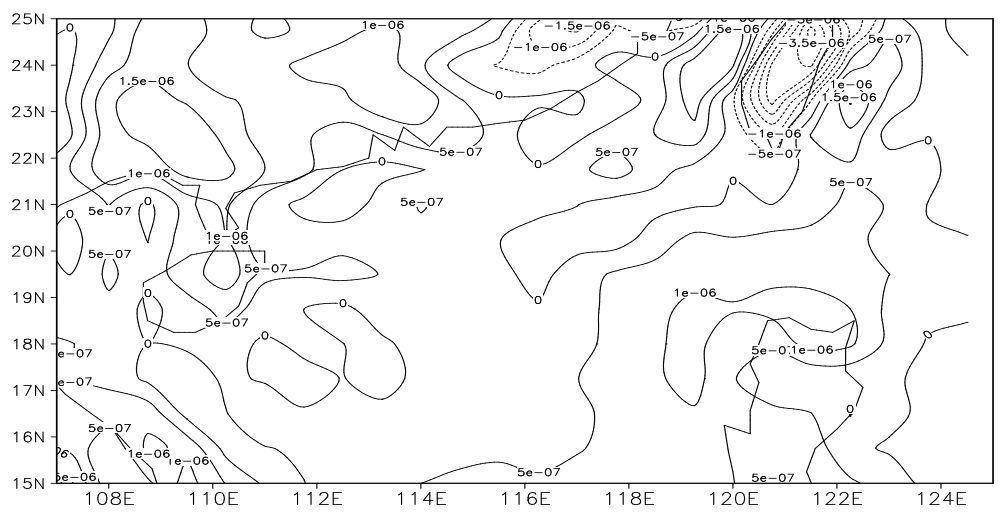

Figure 3. Spatial pattern of the circulation divergence difference between 2004-2008 and 1997-2003 at $925 \mathrm{hPa}$ over South China Sea.

there was a positive divergence difference field over the coastal waters of South China Sea, the signal tended to zero over the central South China Sea, compared to 1997-2003, the low layer of atmosphere showed a stronger divergence over the coastal waters of South China Sea for the years 2004-2008.

The action of the wind set up submergence, forced the surface water of sea subsidence along the windward coast of northwestern South China Sea. Compared to 1997-2003, for the years 2004-2008, SST of the northwes- 
tern South China Sea decreasing and strengthening of low layer atmospheric circulation divergence over it produced a zonal westerly anomaly field (Figure 4), which had an opposite direction to the local northeastern trade wind, leaded to a weaker sinking of surface seawater $(0-10 \mathrm{~m})$ convergence, produced a positive difference of downwelling (Figure 5), in the Reserve.

Results from the expeditions of South China Sea Institute of Oceanology in 2004 and 2008, the coral coverage ratio decreased in the Reserve (Figure 1), and the number of Goniopora duofasciata increased rapidly, which can tolerance high deposition, Goniopora duofasciata replaced the original dominant coral species (Figure omitted). During the expedition, it was also found that there were a lot of fish and shellfish farms near the Reserve, which produced food scraps and pollutants with the water into the Reserve, leaded to an increase of suspended matter in water.

To sum up, the main cause of the coral reef degradation in Xuwen National Coral Reef National Nature Reserve may be: the increasing of suspended matter in water, with the strengthening of divergence in low layer atmosphere, a zonal westerly anomaly and the declining of sea surface temperature, which made the downwelling in northwestern South China Sea decreasing, coupled with strong winds stir the seawater and sediment, a plurality of strong tropical cyclones affecting Leizhou Peninsula from 2005 to 2008 [10] [11], made the water quality deteriorating, water transparency decreased significantly, coral reef survival environment worsened, led the degradation of coral reef building capacity in the Reserve. Continued monitoring efforts are necessary to further assess the relationship between coral building capacity and in situ meteorological factors anomalies and improve the use of the dataset in future regional degradation predictions.

\section{Conclusion}

1) For the years 2004-2008, the temperature of surface coastal water in South China Sea dropped significantly,

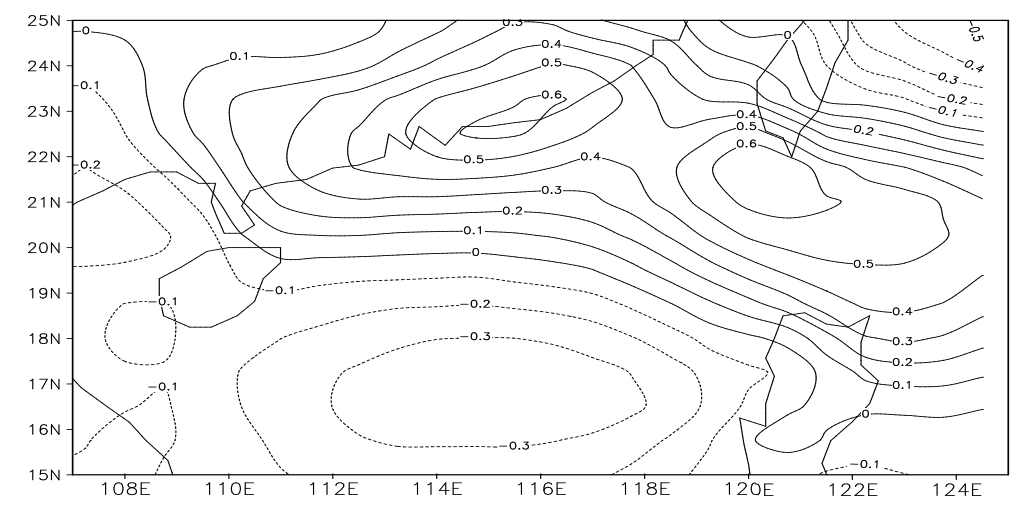

Figure 4. Spatial pattern of $U$ component of wind difference $(\mathrm{m} / \mathrm{s})$ between 2004-2008 and 1997-2003 in the offshore of South China Sea.

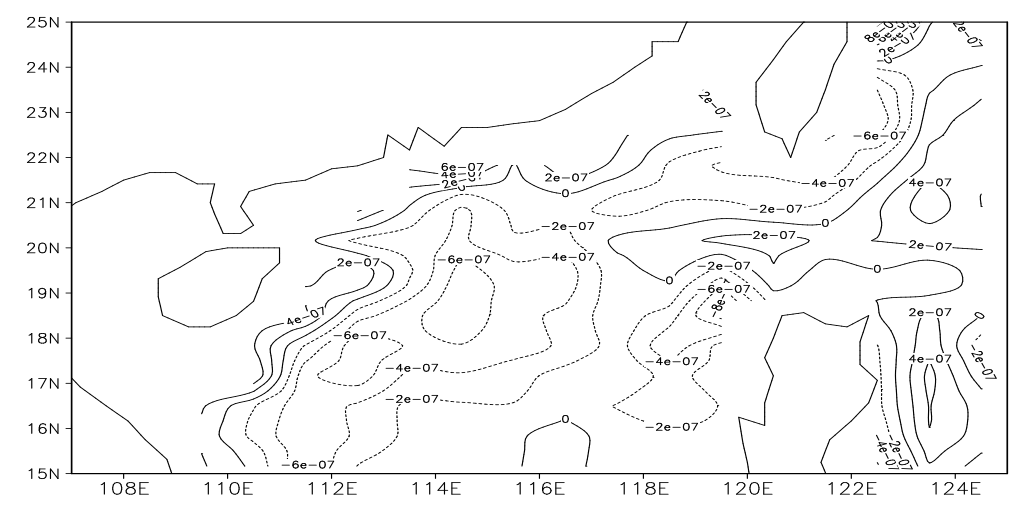

Figure 5. Spatial pattern of surface seawater $(0-10 \mathrm{~m})$ downwelling difference $(\mathrm{m} / \mathrm{s})$ between 2004-2008 and 1997-2003 in the offshore of South China Sea. 
compared to $1997-2003$, SST of the Reserve dropped by $-0.5^{\circ} \mathrm{C}$.

2) Compared to 1997-2003, the low layer of atmosphere showed a stronger divergence over the coastal waters of South China Sea for the years 2004-2008.

3) Compared to 1997-2003, a zonal westerly anomaly field was produced over the northwestern South China Sea, which had an opposite direction to the local northeastern trade wind, leaded to a weaker sinking of seawater convergence for the years 2004-2008.

The increasing of suspended matter in water, the decreasing of downwelling in northwestern South China Sea, coupled with strong winds stir the seawater and sediment, made the water quality deteriorating, water transparency decreased significantly, coral reef survival environment worsened, these would cause adverse effects on coral reef building capacity in Xuwen National Coral Reef National Nature Reserve.

\section{References}

[1] Yu, K.-F., Zhao, J.-X., Wei, G.-J., et al. (2005) $\delta^{18} \mathrm{O}, \mathrm{Sr} / \mathrm{Ca}$ and $\mathrm{Mg} / \mathrm{Ca}$ Records of Porites lutea Corals from Leizhou Peninsula, Northern South China Sea, and Their Applicability as Paleoclimatic Indicators. Palaeogeography, Palaeoclimatology, Palaeoecology, 218, 57-73.

[2] Wei, G.-J., Sun, M., Li, X.-H., et al. Mg/Ca, Sr/Ca and U/Ca Ratios of a Porites coral from Sanya Bay, Hainan Island, South China Sea and Their Relationships to Sea Surface Temperature. Palaeogeography Palaeoclimatology Palaeoecology, 162, 59-74.

[3] Wei, G.-J., Deng, W.-F., Yu, K.-F., et al. (2007) Sea Surface Temperature Records in the Northern South China Sea from Middle Holocene Coral Sr/Ca Ratios. Paleoceanography, 22, 1-13.

[4] Sun, Y.-L., Sun, M., Wei, G.-J., et al. (2004) Strontium Contents of a Porites coral from Xisha Island, South China Sea: A Proxy for Sea-Surface Temperature of the 20th Century. Paleoceanography, 19, 1-10.

[5] Marshall, P.A. and Schuttenberg, H. (2006) A Reef Manager's Guide to Coral Bleaching. Great Barrier Reef Marine Park Authority, Townsville, 163.

[6] Krishnan, P., Roy, S.D., George, G., et al. (2011) Elevated Sea Surface Temperature during May 2010 Induces Mass Bleaching of Corals in the Andaman. Current Science, 100, 111-117.

[7] Zhao, M.-X., Yu, K.-F., Zhang, Q.-M., et al. (2012) Long-Term Decline of a Fringing Coral Reef in the Northern South China Sea. Journal of Coastal Research, 28, 1088-1099.

[8] Bellwood, D.R., Hughes, T.P., Folke, C., et al. (2004) Confronting the Coral Reef Crisis. Nature, 429, 827-833. http://dx.doi.org/10.1038/nature02691

[9] Casey, K.S., Brandon, T.B., Cornillon, P., et al. (2010) The Past, Present and Future of the AVHRR Pathfinder SST Program. In: Barale, V., Gower, J.F.R. and Alberotanza, L., Eds., Oceanography from Space: Revisited, Springer. http://dx.doi.org/10.1007/978-90-481-8681-5_16

[10] Zhang, J.-Y., Wu, L.-G. and Zhang, Q. (2011) Tropical Cyclone Damages in China under the Background of Global Warming. Journal of Tropical Meteorology, 27, 442-454.

[11] Xu, X.-C., Yu, Y.-B. and Zhao, D.-J. (2009) Variational Characteristics of Tropical Cyclones Making Landfall in China with Different Intensity. Journal of Tropical Meteorology, 25, 667-674. 